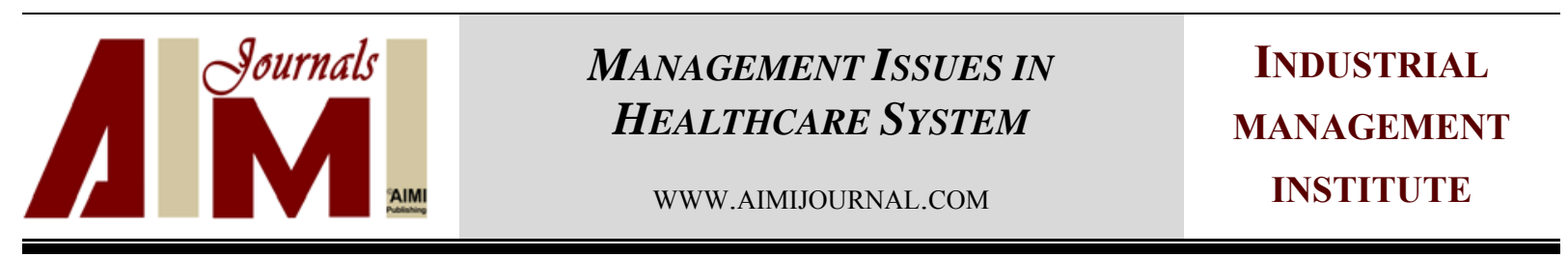

\title{
Contracting services with medical doctors as a form of employment and remuneration - the polish experience
}

\author{
Hanna Karaszewska $^{1^{*}}$, Joanna Nieżurawska ${ }^{2}$, Marek Zarębski ${ }^{3}$ \\ ${ }^{1}$ UMK, Department of Human Resource Management,Nicolaus Copernicus University Torun Poland \\ ${ }^{2} \mathrm{PhD}$, Management Department, Faculty of Finance and Management, Torun School of Banking \\ ${ }^{3}$ UMK, Department of Logistic, Nicolaus Copernicus University Torun Poland
}

\begin{abstract}
Keywords:

gossips, functions of gossips, organization, stress,

organizational interests

Correspondence:

a.dziadkiewicz@hotmail.com

Contracting medical services is becoming a more and more popular form of remuneration of doctors. The principles of rewarding defined in civil contracts in Poland are similar in both public and non-public entities that depend on the kind of contract concluded. The main aim of the research was carrying out an evaluation of the advantages and dangers related to civil contracts as a form of employment and remuneration of doctors in medical health care units. Detailed aims included the identification of the types of remunerations for doctors and defining the determinants of the remunerations of the doctors on civil contracts against the background of the analogical employees. The managers of health care units participated in the study. The research was conducted in two stages. At the first stage, the questionnaire survey method was applied and since the readiness of health care entities in Poland to participate in this kind of research is systematically declining, the number of questionnaires obtained in 2014 was far from satisfactory; so, the method of expert interview came into use. The reform of the healthcare system in Poland was the reason of the necessity of looking at labor costs more carefully. This led to the process of increasing the flexibility of employment in different forms of contracting health services with doctors.
\end{abstract}

(C)AIMI Journals

\section{Introduction}

In 1991, there began the process of radical changes in financing and organizational stabilization of the institution of health care in Poland. By the act on general insurance the Siemaszko model which was in force up to the year 1989, was replaced by an insurance model based with modifications on Bismarck's conception. The functions of providing the funds (the payer i.e. the institution of health insurance) were taken over by the Health 
Insurance Fund and later by the National Health Fund. They distributed the means derived from the targeted tax i.e. health care insurance premiums. The planning functions were handed over to local self-governments. They became the owners of the property as well as the public organs responsible for providing the population with health care services. The Ministry of Health started to fulfill the central level functions. Leading an adequate health care policy, supervision and partial financing of the system had become its imperative tasks. It was the intention of the legislator to enforce new behaviors in the entities participating in the system on both sides.

The health care reform was conducted at three levels including at that of administration (Golinowska et al., 2002), ownership, and financing. Next, the change of the structures creating and providing health care benefits took place. It has resulted in the transformation of budget units into autonomous medical care units (medicinal entities), most of which have acquired the status of non-public units, the establishment of the practice of family doctors and of group practices as well as the practices of medical specialists. The Act on Universal Health Insurance defined the conditions which the service provider must meet. In addition to health care units (hospitals, old-age care and medicinal plants, general and nursing care units, sanatoriums, preventoriums and other entities for people requiring day-and-night health care in an adequate room, health centres, outpatient clinics, emergency service centres, diagnostic laboratories, stomatological prosthetics and orthodontia laboratories, curative rehabilitation units, nurseries) it can be the persons doing a medical job as self-employed individuals or freelance specialists as well as the persons authorized to render health services within the framework of their own registered business activity.

The principles of financing of the new structures have changed. Contracts have replaced the manner of financing that had been applied in budget so far or in the case of the entities rendering commercial services. It has generated the multiplicity of financing sources including the insuring institutions, the state budget sources in the case of highly specialist health services or those covered within the framework of health programmers realized by self-governing authorities, employers, private insurers, and households.

\section{Employment on Contract - Legal Regulations}

Health care reform has introduced several new options of employment for medical doctors. In addition to employment in an autonomous health care unit, it has created the possibility for doctors (service providers) to enter into a health service contract with the Health Insurance Fund/National Health Fund (NFZ). The concluded contract has the character of a civil contract and may be regarded as a separate type of contract.

Employment of a doctor in a ZOZ (health care unit) may have place as a result of entering by him or her into an employment contract (full-time job) or a civil contract.

Employment under an employment contract is based on the regulations of the Labour Code Act of June 26, 1974. Under that contract the physician renders subordinated work on behalf of the employer and uses all the privileges which adds up to the classical employment relationship. 
The most important feature of the medical doctor's contract is the fact that the physician acts on the basis of registered business activity. The medical contract is a commitment agreement based on Civil Code regulations. Under that contract, the respective health care unit and the doctor are equal parties in employment relationship. In case of a patient claiming damage in connection with an error in medical art, the health care unit and the doctor jointly share the liability up to the full value of the claim.

When rendering services under a civil contract the doctor retains a greater degree of freedom but loses the privileges related to the protection of the traditional employment relationship and the related rights.

\section{Reasons for Development of Contract Employment}

Although the first employment contracts appeared in Poland in 2001, their noticeable expansion in closed health care units (hospitals) had place in 2007. Many factors were involved here. Medical doctors and nurses' pay rise claims articulated in the course of medical staff's strikes. In addition, increase of the costs of remunerations as well as the problems with the personnel, occurring especially within the hospital system (Rożko, 2013) caused among others by the resolution of the EU directive 2003/88/WE concerning the working hours. According to the interpretation by the European Tribunal of Justice in relation to medical doctors' duty hours, the time spent at work in readiness to undertake it ranks as working time. In accordance with the above interpretation, also medical doctors' duty hours are counted in the standards for the maximum working time in the case of employment under employment contract. The so-far applied legal regulations in the Polish legislature have been in conflict with the above (i.e. not counting doctors' duty hours in the standards for working time). The need of adjustments to the EU requirements has generated the necessity of reorganization of the working time by health care units and in face of the need, it necessitated meeting the employment standards and the additional employment.

Other factors involve the increase of the requirements concerning the qualifications and number of specialized medical personnel rendering services under contracts with the National Health Fund; necessity of meeting higher payment expectations of doctors resulting among others from taking a different point of reference in the estimation of their own remuneration (EU perspective); functioning in more and more difficult conditions because of the competition (dynamic development of non-public health care service); and increasingly noticeable need to search for tools of plasticization of employment, remunerations, and the working time.

Considering the data provided by the Ministry of Health, in the years 2007-2013 in public hospitals in Poland the number of medical doctors employed under employment contract exceeded the number of doctors on civil contracts. However, the proportion of civil contract employment has been systematically increasing. A group of contract physicians increased twice in the analyzed period and in 2013 for the first time became more numerous than that of specialized doctors employed under employment contract. Medical contracts in the nonpublic health care sector are, basically speaking, very common. It may be assumed that in the years to come, there will have place a further expansion of civil contracts. 


\section{Kinds of Contract Employment}

Medical contracts may assume various forms depending on the job components to which the parties to the contract will attach more importance:

Comprehensive Contracts - contracts which involve health benefits performed by the employee independently of the time of day. Contracts of this kind are most often applied to prevent doctors from escaping to other posts or due to the need of expanding the unit's activity over the standard working hours, limited in employment under the Labor Code.

Duty-Hours Contracts - consist of a civil contract on duty hours by the doctors employed in the same unit and performing there their daily duties under an employment contract. Duty-hours contracts are quite a controversial solution, as there exists a regulation forbidding the employer to conclude a civil contract with an employee on the same activities that he/she performs under the already signed employment contract. The most frequent solution to this problem is to redefine the tasks of the employee under a separate contract (Kijak, 2004).

On-the-Phone Contracts - remaining in readiness to work and working after a telephone call to work. According to the EU Directive such duty hours are not counted in the standards for the working time of medical employees and therefore, there are no standards which would define how many hours of this type of duty may be worked out by the doctor in the week.

However, also the number of hours in an emergency service centre is limited. Since January 1, 2008, work on call is defined as work beyond the normal working hours. This means that, in accordance with the definition of medical duty hours, the performance of professional activities beyond the standard working hours by the doctor is a fulfillment of a medical duty by him/her. In this way, the exploitation of the allowable monthly limit of overtime hours by the employer is equal to the number of on-the-phone contracts granted which the unit can allocate. If the unit manager wrongly allocates duty hours, there may occur a situation in which he/she would not be able to effectively call a doctor to perform his/her professional duties.

A health care unit may decide to contract not only one medical service, but choose a package option. The set of the contracted service may involve some factors, namely medical doctor's service, medical doctor's service and a nursing service, and medical doctor's service along with the cost of medication and a refund for the use of the private equipment belonging to the doctor.

\section{Method}

The main aim of the research was carrying out an evaluation of the advantages and dangers related to civil contracts as a form of employment and remuneration of doctors in medical health care units.

Detailed aims include the identification of the types of remunerations for doctors and defining the determinants of the remunerations of the doctors on civil contracts against the 
background of the analogical employees.

The research was conducted in two stages. At the first stage, the questionnaire survey method was applied (Karaszewska \& Nieżurawska, 2013). Considering the fact that the readiness of health care entities in Poland to participate in this kind of research is systematically declining, the number of questionnaires obtained in 2014 (they were intended to constitute the main study) was far from satisfactory. Therefore, it was decided to use the method of expert interview. The participants of the interview were managers of health care units - the participants of the project Copernican Academy of Health Manager, financed from the funds of the European Social Fund realized by the Faculty of Economic Sciences and Management at the Nicolaus Copernicus University in Torun.

\section{Advantages and Dangers Related to Civil Contracts}

Experts were asked to formulate the main advantages resulting from the introduction of medical services contracting by doctors as independent health care entities.

The basic advantage of medical contracts pointed out by the interviewees (Figure 1) was the acquisition of a tool of plasticization of employment and working time management (the possibility of making the working time longer, greater availability of employees). Over fifty per cent of the experts also pointed out the cost saving due to the decreased taxing and expenditures on social benefits. The experts representing the non-public sector more often (50\% of indications) than the managers of the public health care units $(40 \%)$ pointed out improvement in the quality of services rendered by doctors. An interesting outcome of the study is the fact of indicating in it a better patient-doctor relationship, almost exclusively by the representatives of non-public health care units (41.7\%).

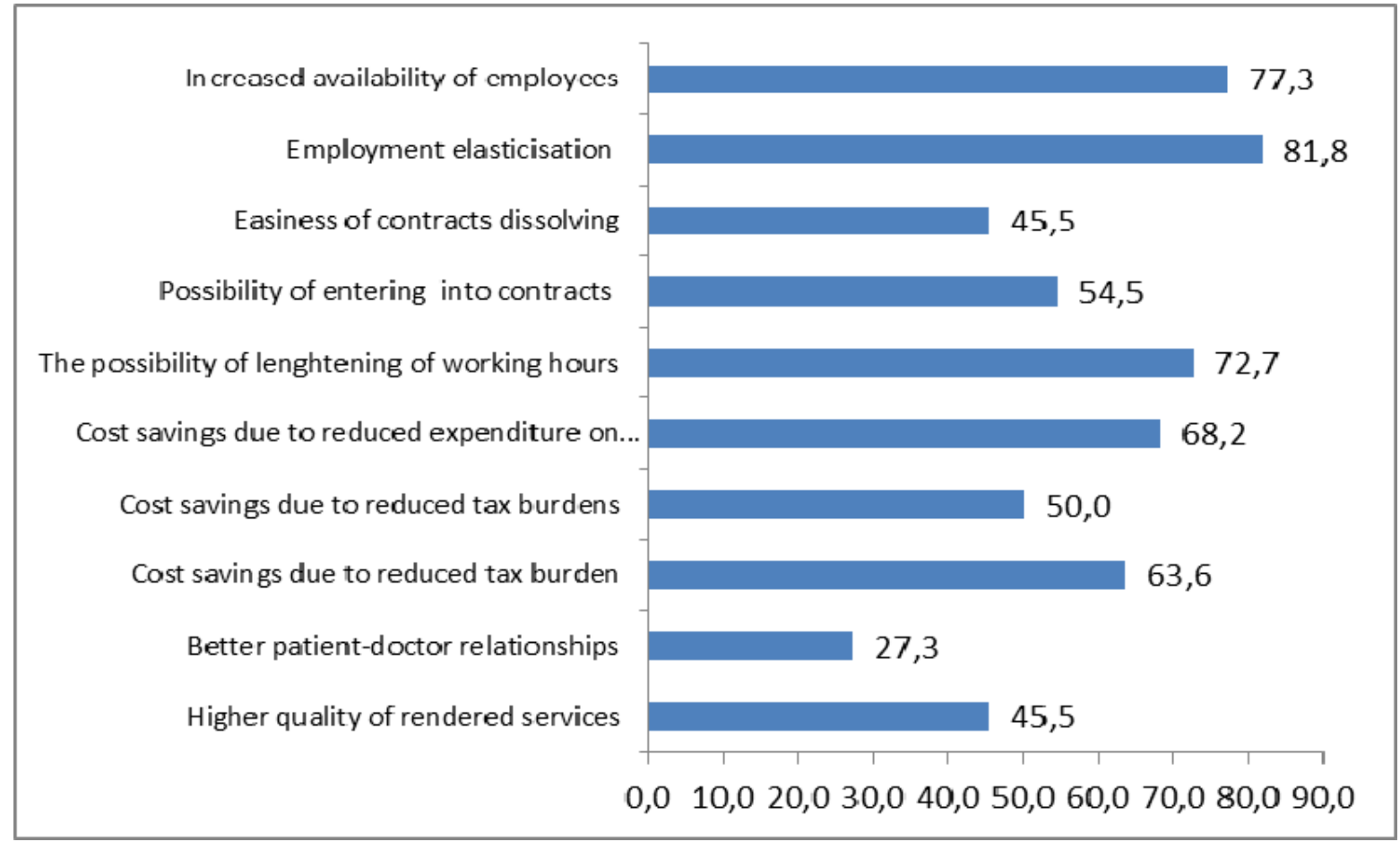

Figure 1. Advantages of civil contracts concluded with doctors in health care units in Poland (in \%) 
As the basic danger, the experts perceive the growth of contract workers' payments and loosening of ties between doctors and their workplace (Figure 2) (in Poland contract doctors often work in several locations, rendering also commercial services in the form of private practice.) The representatives of the public sector pointed more frequently to the latter limitation. Figure 1 presents the advantages of civil contracts concluded with doctors in health care units in Poland (in \%). Figure 2 shows the limitations of civil contracts concluded with doctors in health care units in Poland (in \%).

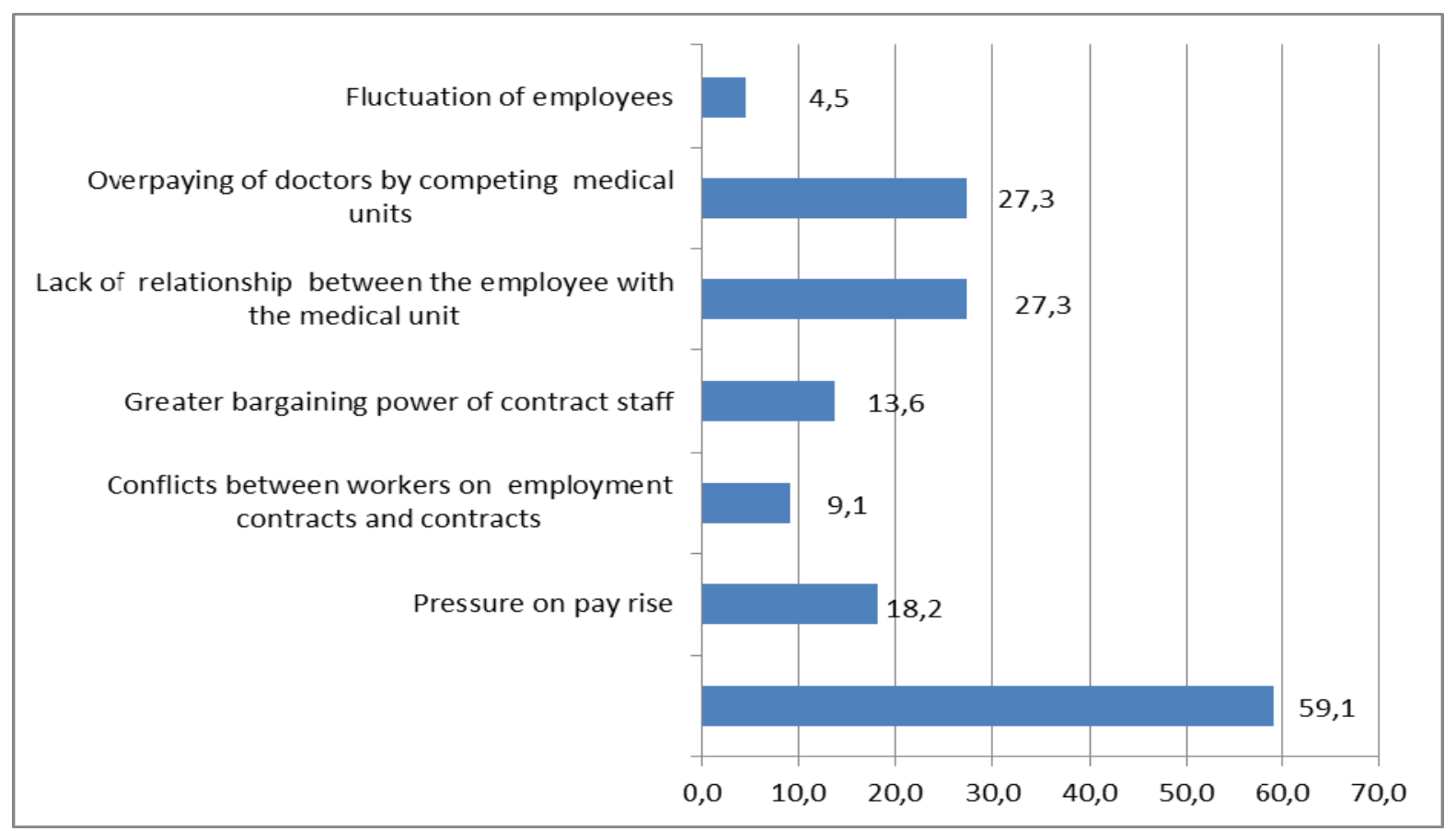

Figure 2. Limitations of civil contracts concluded with doctors in health care units in Poland (in \%)

\section{Types of Contract Remunerations}

The principles of remuneration specified in civil contracts in Poland are similar in both public and non-public entities. They depend on the kind of the concluded contract. In public hospitals, the most frequently applied solutions are hours contract (the doctor's remuneration depends on the number of hours worked out - it separates the payments from the assortment of rendered services. In fact, the principles of counting are the same as those used in shaping the basic pay in employment contracts); task contract - the amount of remuneration depends on the amount of the contract worked out with the NFZ. The basis for its determination is the so-called settlement point; the task contract with percentage or money share from the income worked out from the medical services rendered. It is more effective than hours contract. Its main disadvantage, however, is the fact that in the case of a contract concluded with several doctors who jointly work out the outcome of the ward, each of them gets per cent of the total amount of the sale irrespectively of the scale of their own involvement.

Other solutions are the task contract with percentage share in the income derived from the sale of services realized individually. A doctor's remuneration depends, as before, on the contract worked out with the NFZ. There is, however, a difference in the manner of counting 
of the commission. The doctor gets a commission only if he was the operator of a medical intervention. This type of contract most strongly stimulates job effects; in hours-task contract (a mixed system) the basis of remuneration is the hours contract with lower rates than in a purely hours contract; the remaining part of the remuneration depends on the performance outcomes (a motivational element); and regarding the consultation rates, in open medical care hours contracts are applied, contracts based on a share in the generated incomes, fees for services together with its variation; fees for appointments (each specialist appointment has its point valuation), capitation system (remuneration is made dependent on the number of patients remaining under the care of a given doctor). An interesting solution is the kind of capitation taking into consideration patients' demographical structure used in contracts with family doctors (granting more points to the patients who are in risk groups - elderly persons as well as to extremely difficult patients (e.g. babies). In addition, the localization of the practice, distance, costs of getting to the patient, and the number of doctors of a given specialty in the area are all determinants of the contract.

\section{Determinants of Medical Contracts}

Experts were asked to define the determinants of medical contracts shaping and to rank the indicated factors on the following scale: 0 - unimportant factor, 1- important but not crucial factor, 2- the crucial factor.

The most essential determinants shaping contract remunerations were, according to the experts representing both the public and non-public sector, the type of specialization (weighted average 1.5) and specialization degree (weighted average 1.7) (Figure 3). It is worth noting that the kind of specialization was indicated also as the most important factor of differentiating of the salaries of medical doctors employed on employment contracts (Figure 4). Indication by the managers of health care units of the range of realized procedures as an important salaries differentiating factor (weighted average 1.2) results from the more and more frequent exploitation of task contracts as a form of remuneration. The financial standing of the medical care unit indicated by the totality of entities as an important determinant of remunerations had a greater impact in the entities of the non-public sector. The situation on the labour market was more bitterly experienced in the units of the public sector (weighted average 0.9) than by analogous units in the non-public sector (weighted average 0.6) and particularly by those who employed workers on employment contracts (Figure 4).

The amount of the particular element of a civil contract also depends on the bargaining strength of the people employing themselves, the strength resulting from their high qualifications and from the market position of the service attracting the patient. Some specialists get a higher payment in non-public health care units, especially when their employment is indispensible in the process of fighting to get a contract with the NFZ. For the majority of medical specialists a civil contract concluded with a non-public health care unit constitutes a supplementary remuneration. Table 1 presents the types of remunerations of doctors and their weak and strong points.

Figure 1 and 2 depicts the determinants of remunerations of contract doctors in the health care entities in Poland and determinants of remunerations of the doctors employed under employment contracts in health care units in Poland, respectively. 
Table 1

Types of Remunerations of Doctors and their Weak and Strong Points

\begin{tabular}{|c|c|c|c|}
\hline $\begin{array}{c}\text { Type of } \\
\text { Remuneration }\end{array}$ & Description & Strong Points & Weak Points \\
\hline Fee for service & Remuneration for each service rendered. & $\begin{array}{l}\text { Ties the payment to the range of services realized. } \\
\text { Generates good access to medical care. } \\
\text { Creates the possibility of selection of service } \\
\text { provider. } \\
\text { Favors high quality of health care services. }\end{array}$ & $\begin{array}{l}\text { Encourages choosing expensive } \\
\text { services, raising fees. } \\
\text { The difficulty managing the } \\
\text { payment system due to the great } \\
\text { changeability of the amount and } \\
\text { types of this kind of services. } \\
\text { Complicated cost accounting } \\
\text { Hindered flow of information } \\
\text { between the patient, the service } \\
\text { provider and the payer. }\end{array}$ \\
\hline
\end{tabular}

Capitation Monthly remuneration is dependent on the number of patients remaining under the care of a medical doctor independently of the number of services rendered.
Allows to ensure a full-profile medical care

Increases the doctor's responsibility (directing the patient's moving around in the system, education of patients)

Allows for cost control.

Makes the management of the system of payments easier.

Simple accounting of the cost of the care and of the system of information.

$\begin{array}{ll}\begin{array}{c}\text { RVS - Relative } \\ \text { Value Scale }\end{array} & \begin{array}{l}\text { Rejection of bills which differ from the } \\ \text { customary, average and reasonable i.e. used } \\ \text { by the majority of doctors in the preceding } \\ \text { year. }\end{array} \\ \text { Mixed System } & \begin{array}{l}\text { Capitation, fee for the appointment, lump sum } \\ \text { for prophylaxis. }\end{array}\end{array}$

Objectification of payments.

Favors cost rationalization.

Less costly than UCR.

Allows to combine the positive aspects of many systems.
Encourages decreasing the range of one's own services and directing patients to specialists.

Does not involve sufficiently strong motivators to render high quality services.

$\begin{array}{cl}\text { UCR - Usual, } & \begin{array}{l}\text { Rejection of bills which differ from the } \\ \text { customary, average and reasonable i.e. used }\end{array} \\ \text { and Reasonable } & \begin{array}{l}\text { by the majority of doctors in the preceding } \\ \text { year. }\end{array}\end{array}$

Enormous number of procedures being subject to valuation and difficulty valuating some of them Increase in the number of points (code creep) with the same number of services rendered.

Difficulty managing payments

\section{USA-specific}

Eliminates the necessity of costly valuation of Cost rise.

RBRVS - The table of the relative value of services, Resource- which is established by the government, Based Relative which in the USA is responsible for the Value Scale realization of the Medicare Program. The determinants of the value of services are the doctor's working time, the intensification of efforts, the costs of the undertaken actions, the costs of the specialist training.

Payment for Takes into consideration payment for specific Coordination services in coordinating medical care, usually with the particular types of service providers The most typical example of that is the mode of old-age care and medicinal plant where the service provider gets paid for ensuring the coordination of services which are not provided by other entities and for which the costs are not refunded.

Among the types of care in which the payment for coordination is used there is the basic health care, the care for patients with chronic diseases and the care for healthy patients at risk from chronic diseases. many procedures.

In the USA limits the impact of the competition for the doctors realizing services within the framework of coordinated health care.
Allows to take into consideration the multiplicity of determinants defining difficulty of procedures.
Striking disproportions in salaries.

Reflects a big range of interference of the State in market mechanisms.

Improvement and perfection of the relation: doctor-patient, including in particular the communication between the patients and the careers.

Increase in the level of the patient's and his or her family participation in the decisions concerning the care. Improvement of liquidity concerning the issue of how, where and by whom a particular kind of care should be ensured.

Restrictions on sending unnecessary and ineffective care (e.g. a visit in an emergency centre for the cases which should rather be examined in the doctor's office) and thus enhancing the effectiveness of the health care system.
Many patients can suppose or expect that coordination of care will be ensured without an extra fee.

The time-consuming character of coordinated services may radically limit the number of patients -the receivers of those services. 


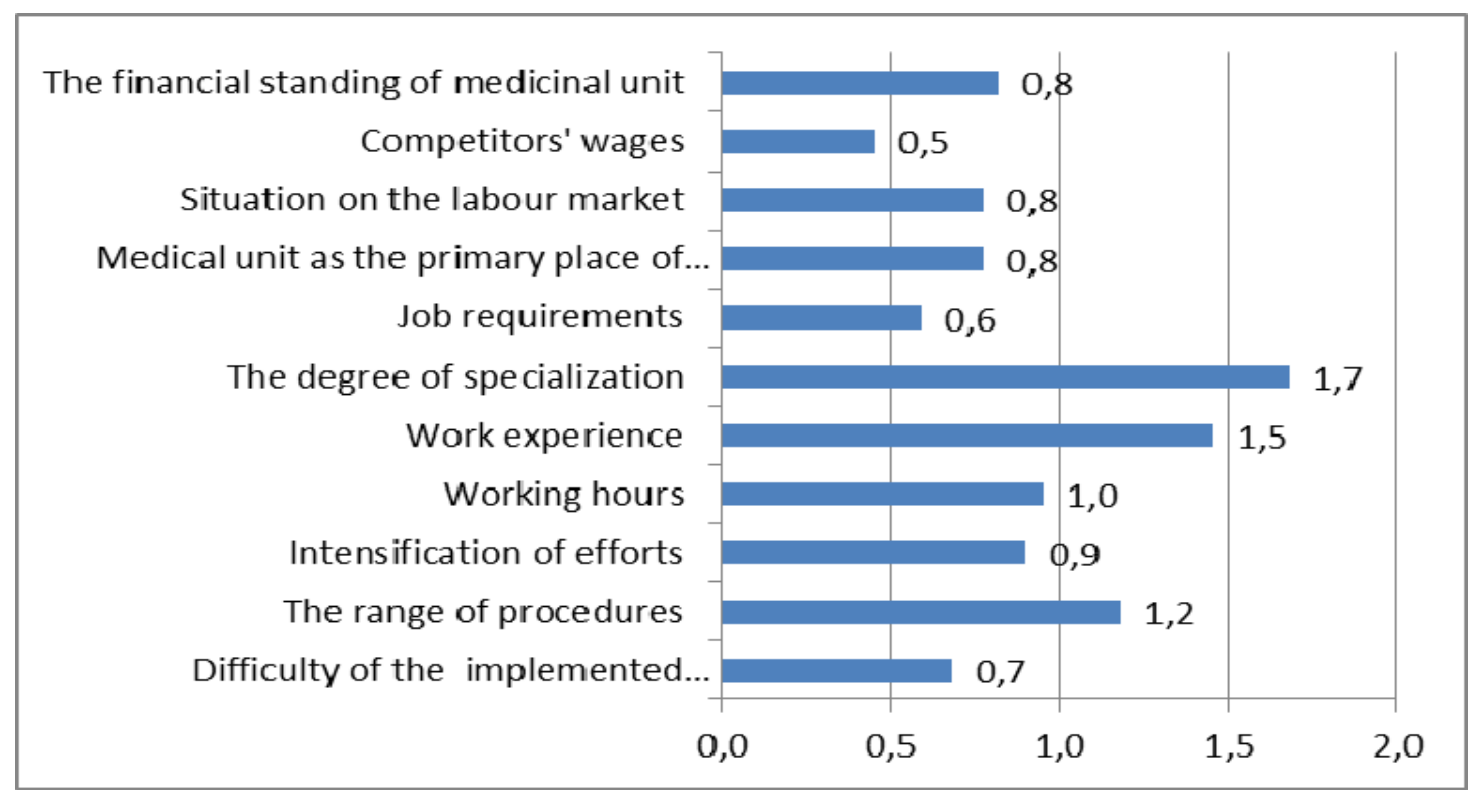

Figure 3. Determinants of remunerations of contract doctors in the health care entities in Poland (Significance Index)

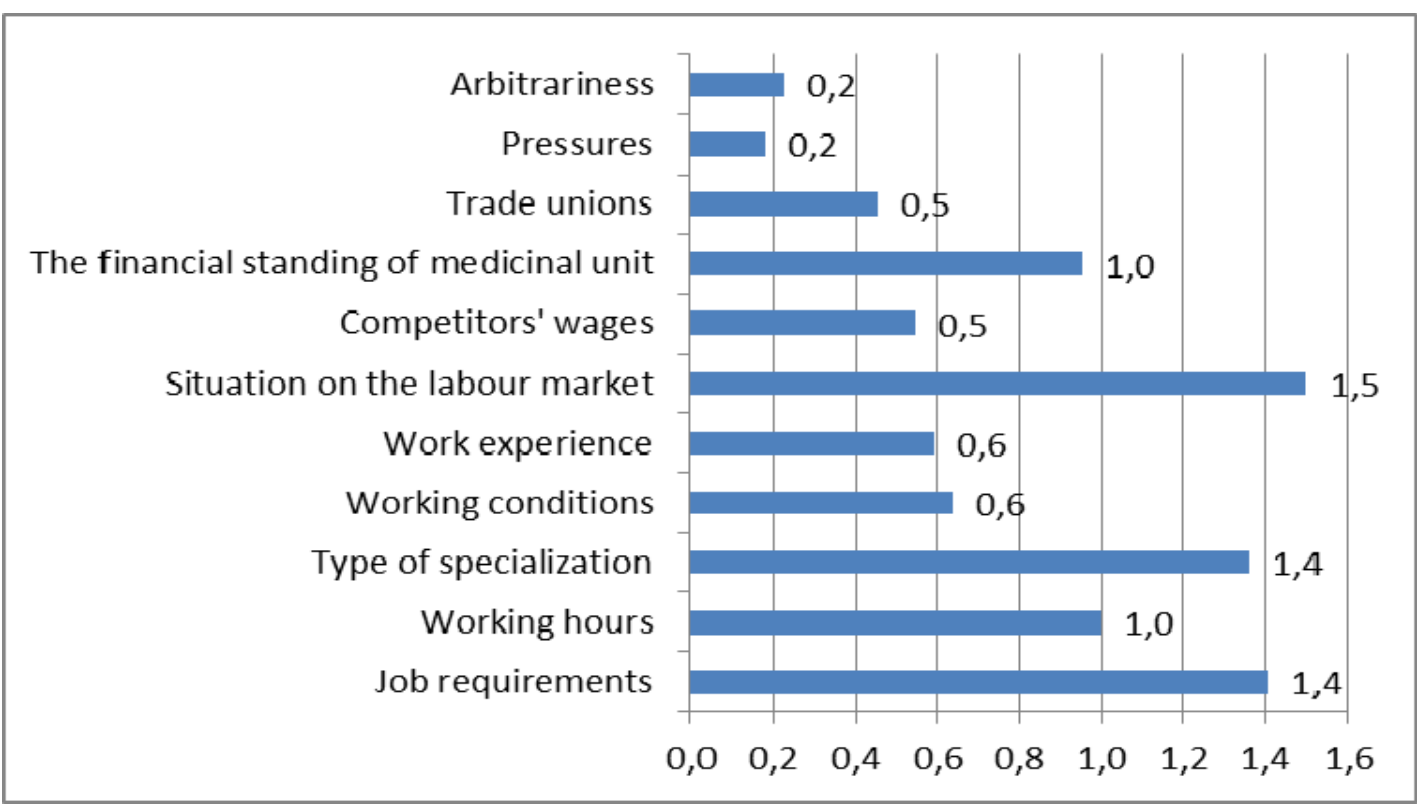

Figure 4. Determinants of remunerations of the doctors employed under employment contracts in health care units in Poland (weighed average)

\section{Conclusion}

Contracting medical services is becoming a more and more popular form of remuneration of doctors. The evaluation of civil contracts, however, is ambiguous. They were mainly introduced to cut on the labour costs (lowering of tax burdens); they have become a tool of management of the working time and of the adjustment of employment to the changing conditions. 
In many cases, they were used as a pretext for pay rise claims, fulfilment of which has generated the increase of the relative costs of employment (contract employees' payments have become higher than their initial gross dimension was - taking into consideration tax burdens). In Poland, the situation of employing contract doctors in many localities have resulted in loosening doctors' ties with their main employer.

The principles of rewarding defined in civil contracts in Poland are similar in both public and non-public entities that depend on the kind of contract concluded. In public hospitals the most commonly used contracts are hours contract, task contract, task contract with percentage or money share from the income derived from the medical services rendered, task contract with percentage share in the income from the sale of services realized individually, hours and task contract (mixed system), and the consultancy rate. Irrespective of the form of ownership, the most frequently used form of contract remuneration in health centers is FFS. Irrespective of the form of ownership of a medicinal entity and of the form of employment (civil contract vs employment contract), the most essential determinant of doctors' remuneration is the kind and degree of specialization. A relatively strong impact of the range of realized procedures results from increasingly frequently applied task contracts.

The weakness of the determinant constituted by the financial standing of the entities from the public sector has probably resulted to a large extent from staff shortages and increasingly experienced pay rise pressures.

The reform of the healthcare system in Poland was the reason of the necessity of looking at labor costs more carefully. This led to the process of increasing the flexibility of employment in different forms of contracting health services with doctors. The dynamic development of contracts after 2007 was accompanied by a number of new conditions. EU legislation involving working time standards and employment aimed at improving the quality of health services coexisting with the emigration of a large group of medical workers associated with the opening up of labor markets resulted in more and more acutely staffing shortages, against whom stood therapeutic entities in Poland. This caused that the contracts that were supposed to generate cost savings have become primarily a tool for the reorganization of working time. Pressures on the wages of contract workers was the reason that in many entities salary increased independent of their financial situation. It also contributed to a loosening of bonds among medics. The results of studies using expert interview probing the benefits and risks of contractual agreements with doctors, their determinants in therapeutic entities in Poland were included in the current study.

\section{References}

Golinowska S., Czepulis- Rutkowska, Z., Sitek, M., Sowa, A., Sowada, C., \& Włodarczyk, C. (2002). Opieka zdrowotna w Polsce po reformie, (Health Care in Poland after the Reform). Raporty CASE, Warszawa.

Karaszewska H., \& Nieżurawska, J. (2013). Wynagradzanie w podmiotach leczniczych w Polsce (Remunerations in health care units in Poland). Zarządzanie Zasobami Ludzkimi,Komitet Nauk o Pracy i Polityce Społecznej PAN, Instytut Pracy i Spraw Socjalnych.

Kijak, R. (2004). Dyżur medyczny, polski anachronizm (Medical duty hours, a Polish anachronism). Służba Zdrowia.

Rożko, K. (2013). Szpitale powiatowe szukają specjalistów (County Hospitals on the Lookout for Specialists). Rynek Zdrowia. 